\title{
Journal of Immunology and Allergy
}

\section{Milmed Treatment Alleviates Symptoms of Allergy and Improves General Health}

\author{
Trevor Archer ${ }^{\mathbf{1}^{*}}$, Rose Mary Erixon ${ }^{1,2}$, Thomas Lenz ${ }^{1}$ and Rita \\ Businaro $^{3}$
}

\begin{abstract}
The effects of the patented treated-yeast, Saccharomyces cerevisiae, a probiotic suspension which was shown earlier to present neuroprotective and neurorestorative properties, upon allergies presented by a group $(\mathrm{n}=8)$ of patients, that were compared with a matched group of patients administered untreated yeast cells $(n=8)$. Treated yeast cells were subjected to millimeter-wave exposure as outlined in patented documents. The patients who administered themselves treated Milmed, over periods extending from four-tothirteen weeks, completed subjective self-report ratings of their allergy symptoms that indicated marked ameliorative effects; additionally, they rated their general health situations to be markedly improved. Those patients who had taken the untreated yeast did not report these improvements. Correlational analyses between the number of weeks treated Milmed was taken by patients and (i) alleviation of allergy symptoms, and (ii) improvement in general health status, indicated significant relationships in each case. The significant correlations
\end{abstract} between symptom improvements and general health status, on one hand, and the number of weeks treated Milmed was ingested imply that complete treatments are required for the optimal therapeutic benefits. As observed previously, 8-to-13-week episodes of treated Milmed self-administration provides a lasting amelioration from allergy symptoms and an improved general health status.

Keywords: Allergy; Patients; Milmed treatment; Millimeter waves; Allergy symptoms; General health; Amelioration; Frequency; Improvement; Correlation; Probiotics.

\section{Introduction}

A large proportion of individuals (up to and above $20 \%$ of adults) are sufferers from allergic rhinitis and related allergies among the Western and the industrialised countries. The incidence of globallyoccurring rhinitis allergies, with more-or less with seasonal dependence, and/or food-related allergies has shown
${ }^{1}$ Milmed Unico AB, Regeringsgatan 93, Stockholm, Sweden

${ }^{2}$ University of Gothenburg, Department of Psychology, Gothenburg, Sweden

${ }^{3}$ Sapienza University of Rome, Department of Medico-Surgical Sciences and Bio techniques, Rome, Italy

*Corresponding Author: Trevor Archer, Milmed Unico AB, Regeringsgatan 93 , Stockholm, Sweden.

Received Date: 10-05-2020

Published Date: 11-06-2020

Copyright $^{\odot} 2020$ by Archer T, et al. All rights reserved. This is an open access article distributed under the terms of the Creative Commons Attribution License, which permits unrestricted use, distribution, and reproduction in any medium, provided the original author and source are credited. 
types of hyper reactivity to otherwise commonly-occurring and neutral substances. These 'allergens', due to their allergy-inducing properties, may involve 'aero-allergens', such as dust mite, mold, tree weed and grass pollen, and 'foodallergens', such as peanuts, milk, egg, soy, wheat, nut and/or fish proteins [3-5]. These allergy symptoms encompass reddening of the eyes, persistent itchy rashes, nasal itchiness, reactions within the roof of the mouth, throat, eyes, sneezing, a stuffy nose (presenting nasal congestion), and runny noses, tears running from the eyes, a shortness of breath, or swelling. Food allergies may present with vomiting, instances of diarrhea, respiratory symptoms and/or anaphylaxis immediately after ingestion of the allergen. Allergyrelated disorders include different instigators of hay fever (allergic rhinitis), asthma, allergic eyes (allergic conjunctivitis), allergic eczema, hives (urticaria), and allergic shock, which is even called anaphylaxis and/or anaphylactic shock [6]. The treatment and convalescence from allergy reactions are remarkable for their diversity, selectivity and lack of sufficient predictability for both sufferers and their eventual caregivers [79]. Due to the increasing levels of allergic reactions among individuals in western industrialised countries the development of evidence-based primary and secondary prevention issues of allergic conditions has been discussed [10]. Performed on yeast culture Saccharomyces carlsbergensis strengthen the effect by resorting to synchronization oscillations in the cells when exposed them to millimeter radiation: in this case the amplitude of sync oscillations could be substantially greater than at bare mutual synchronization. The 'Millimeter -waves'
(MWs) notion applies to a relatively narrow range of electro-magnetic waves with wavelengths from 1 to $10 \mathrm{~mm}$, applicable for medical purposes [11-13], such as 'Millimetre Wave Therapy' (MW therapy), 'Extremely High Frequency EHF therapy', 'Microwave Resonance Therapy' (corresponding to frequencies from 300 to $30 \mathrm{GHz}$, with $1 \mathrm{GHz}=109$ oscillations per second). MW therapy has proven effective for the treatment of a wide range of inflammatory ailments, including gastrointestinal diseases [14], diabetes [15], wound-healing [16], and homeostasis restoration [17-19], as well as healing infections in laboratory animal studies [20]. Taken together, the above and a wide range of other clinical and laboratory studies have underlined the therapeutic propensities of MW applications over a plethora of inflammatory conditions [21]. Nevertheless, the direct application of millimetre waves, though efficacious, may both potentially and apparently prove damaging to the tissues exposed. It has been observed that specific biological and therapeutic effects of Extremely High Frequency (EHF) electromagnetic fields may be transferred to living organisms by specially treated suspension of living yeast cells $[\mathbf{2 2 , 1 8 ]}$. The treatment of yeast cell cultures themselves, as the "transferenceagent" provides an agent that has been shown provide both anti-parkinson and anti-neurodegenerative effect [23-25] in addition to an anti-allergy effect [26]. The treatment and preparation of $S$. cerevisiae or $S$. carlsbergsis with electromagnetic waves in the Extreme High Frequency (EHF) range of $30-300 \mathrm{GHz}$ produces a treated yeast extract, given the name Milmed (i.e. Milmed). This treatment was developed through the pioneering work of Golant [27,28] upon the genesis and 
reparation of cells. Nevertheless, the status of EHF, a complementary and/or alternative medicine, remains unproven to some degree albiet with a level of safety, and further experimentation is currently underway, despite the lack of World Health Organisation (WHO) recommendations. The present study presents a follow-up to the ist study on the effects of treatment with yeast cells according to the patent application (herein referred to as Milmed treatment) upon ongoing allergy symptoms among sufferers [29]. Previously, it was observed that allergy symptoms were alleviated among the patients studied, but in that study each patient was used as his or her own control through which the level of allergy was compared before and after the Milmed treatment. In this study, a control group of patients treated for 8 weeks with a composition comprising untreated yeast cells was compared with a group of patients treated for 4 to 13 weeks (median: 9 weeks) with Milmed, i.e. a composition comprising yeast cells according to the patent application. The procedures and methods applied previously [29] were repeated. The purpose of this study was to (i) test the putative interventional effects of Milmed upon allergy symptoms by comparisons of treated and untreated groups, and (ii) to replicate and extend the findings of the previous study (ibid).

\section{Method and materials}

\section{Un-treated yeast cells}

A liquid composition comprising untreated yeast cells was evaluated in a study performed during the time period of April 21 to June 15, 2020. The composition contained Saccharomyces cerevisiae (which had not been treated as described in the application) at an amount of $30 \times 106$ CFUs/ml suspended in sterilized wort as described in the patent application. "Normal dose" refers to $200 \mathrm{ml}$ of the composition per week.

\section{Treated yeast cells}

A liquid composition as described in the patent application was evaluated in a study performed during the time period of March 17 to June 24, 2020. The composition contained Saccharomyces cerevisiae (DSM 33148) at an amount of $30 \times 106 \mathrm{CFUs} / \mathrm{ml}$ suspended in sterilized wort as described in the patent application. The yeast cells (Saccharomyces cerevisiae (DSM 33148)) had been treated as in the patent application. "Normal dose" refers to $200 \mathrm{ml}$ of the composition per week.

\section{Participants}

Sixteen patients presenting allergic problems (Males=8; Females=8), with ages ranging from 30 to 71-years-of-age $($ median $=45.0)$, participated in the study.

The patients were recruited through wordof-mouth contacts among associates and acquaintances as well as announcements that identified individuals who expressed an interest due to ongoing allergy difficulties, and all expressed the desire to receive some form of respite from their allergy problems, which were debilitating to a greater or lesser degree.

\section{Group receiving untreated yeast cells - "Control" group}

Eight patients presenting allergic problems (Males=3; Females=5), aged from 30 to 65 years-of-age, were treated with untreated yeast cells for 8 weeks. After 8 weeks, each patient rated the perceived improvement on allergy on a scale of 1 to 10 and the 
perceived improvement in general health on a scale of 1 to 10.

Group receiving treated yeast cells "Milmed" group

Eight patients presenting allergic problems (Males=5; Females=3), aged from 30 to 71 years-of-age, were treated with "Milmed" for 4 to 13 weeks. The median treatment time was 9 weeks (see below). After the test period, each patient rated the perceived improvement on allergy on a scale of 1 to 10 and the perceived improvement in general health on a scale of 1 to 10 . The median ( \pm quartile) values were $9.125 \pm 2.25$ ). All patients who were treated for 4-13 weeks reported that they had perceived the same level of improvement on allergy and in general health also after 8 weeks.

\section{Patient Data}

\section{Untreated Milmed group: Descriptions and individual participants' responses}

\section{Patient 1}

Female, 55-years-old, Ex-smoker. Childhood indications; asthma/bronchial problems, allergic rhinitis, food hypersensitivity.

History of allergy: fur, cats, horse and dogs, contact. Throughout the year: rhinorrhea, sneezing; eye itchiness; throat itching. Use of a variety of prescribed medications against fur allergy. Non-genetic. Intake of normal dose from start before breakfast for 8 weeks. Perceived improvement on allergy: scale of 1 to 10 rated self as 1 out of 10; Perceived improvement in general health: scale of 1 to 10 rated self as 1 out of 10.

\section{Patient 2}

Female, 44-years-old, Non-smoker. Childhood indications; Eczema, asthma/bronchial problems, allergic rhinitis, food hypersensitivity. History of allergy: pollen, hazelnut, apple, kiwi, peach. Seasonal, Mars-September. Symptoms: blocked nose, sneezing, itchiness, redness, and swollen eyes; heavy breathing, shortness of breath, pressure in the chest. Medication: desloratadine. Genetic. Intake of normal dose start before breakfast for 8 weeks. Perceived improvement on allergy: scale of 1 to 10 rated self as 1 out of 10; Perceived improvement in general health: scale of 1 to 1o rated self as 1 out of 10 .

\section{Patient 3}

Female, 65-years-old, Non-smoker. No childhood indications. History of allergy: pollen, hazelnut. Seasonal, April-May. Symptoms: allergic rhinitis, sneezing; itchiness and watery eyes; itchiness in throat. Medication: desloratadine. Not genetic. Intake of normal dose start before breakfast for 8 weeks. Perceived improvement on allergy: scale of 1 to 10 rated self as 1 out of 10; Perceived improvement in general health: scale of 1 to 10 rated self as 1 out of 10 .

\section{Patient 4}

Male, 32-years-old. Non-smoker but snuff. Childhood indications; Eczema, allergic rhinitis. History of allergy: pollen, grass, fur, dog, cat, horse. Seasonal, June-July. Symptoms: allergic rhinitis, blocked nose, impaired sense of smell, sneezing; itchiness, watery and swollen eyes; cough. Medication: antihistamine. Genetic. Intake of normal dose start before breakfast for 8 weeks. Perceived improvement on allergy: scale of 1 to 10 rated self as 1 out of 10 ; 
Perceived improvement in general health: scale of 1 to 10 rated self as 2 out of 10 .

\section{Patient 5}

Male, 30-years-old. Non-smoker but snuff. Childhood indications; allergic rhinitis, cardiac asthma (type of coughing or wheezing that occurs with left heart failure). History of allergy: pollen, grass, fur, dog, cat, horse. Seasonal, June-July. Symptoms: allergic rhinitis, blocked nose, impaired sense of smell, sneezing; itchiness, watery and swollen eyes; cough. Medication: antihistamine. Genetic. Intake of normal dose start before breakfast for 8 weeks. Perceived improvement on allergy: scale of 1 to 10 rated self as 1 ; Perceived improvement in general health: scale of 1 to 10 rated self as 2 .

\section{Patient 6}

Female, 44-years-old, Non-smoker. Childhood indications: asthma/bronchial problems, allergic rhinitis. History of allergy: pollen and grass. Seasonal, May August. Symptoms: allergic rhinitis, sneezing; itchiness, redness, and swollen eyes. Medication: desloratadine, rhinocort. Non-genetic. Intake of normal dose start before breakfast for 8 weeks. Perceived improvement on allergy: scale of 1 to 10 rated self as 2 out of 10; Perceived improvement in general health: scale of 1 to 10 rated self as 2 out of 10 .

\section{Patient 7}

Male, 31-years-old. Smoker and snuffer. Childhood indications: allergic rhinitis. History of allergy: pollen, dog fur. Seasonal, Mars-September. Symptoms: blocked nose, sneezing; itchiness in eyes; cough. Intake of normal dose start before breakfast for 8 weeks. Perceived improvement on allergy: scale of 1 to 10 rated self as 2; Perceived improvement in general health: scale of 1 to 10 rated self as 5 , more alert.

\section{Patient 8}

Female, 49-years-old, Non-smoker but snuff user. Childhood indications: eczema. History of allergy: pollen. Seasonal, MarsOctober. Symptoms: allergic rhinitis; itchiness in eyes; cough, shortness of breath. Medication: cyklokapron. Intake of normal dose start before breakfast for 8 weeks. Perceived improvement on allergy: scale of 1 to 10 rated self as 3 out of 10; Perceived improvement in general health: scale of 1 to 10 rated self as 3 out of 10 , reduced bowel- and/or stomach illness/disorders.

\section{Treated Milmed group: participants' descriptions and responses}

\section{Patient 1}

Male, 47-years-old, Non-smoker. Childhood indications; allergic rhinitis. History of allergy: pollen, grass, horses. Seasonal, May-September. Symptoms: blocked nose, sneezing; itchiness in eyes; irritation and itchiness in throat. Medication: insulin, blood pressure medication. Non-genetic. Intake of normal dose start before breakfast for 13 weeks. Perceived improvement on allergy, scale of 1 to 10 rated self as 9; perceived improvement in general health, scale of 1 to 10 rated self as 9, more alert, fewer colds; infections; stomach and bowel disorder; improved sleep since Milmed treatment.

\section{Patient 2}

Male, 71-years-old, Non-smoker. No childhood indications. History of allergy: pollen, dog, cat, horse, odors and mold. 
Seasonal, May-July. Symptoms: allergic rhinitis, sneezing; redness, itchiness and watery eyes; loose mucus. Not genetic. Intake of normal dose start before breakfast for 10 weeks. Perceived improvement on allergy, scale of 1 to 10 rated self as 10; Perceived improvement in general health, scale of 1 to 10 rated self as 8 , fewer infections, colds, and pain in body since Milmed treatment.

\section{Patient 3}

Male, 42-years-old, Non-smoker but snuff. No childhood indications. History of allergy: pollen. Seasonal, April-May. Symptoms: allergic rhinitis, sneezing, lower sense of smell; redness, and watery eyes. Medication; antihistamines. Intake of normal dose start before breakfast for 10 weeks, missed treatment one week. Perceived improvement on allergy, scale of 1 to 10 rated self as 8; Perceived improvement in general health, scale of 1 to 10 rated self as 3, fewer colds since Milmed treatment.

\section{Patient 4}

Female, 41-years-old, 'Party-smoker'. No childhood indications. History of allergy: pollen, cat, chemicals, scents. Seasonal, Mars-September. Symptoms: allergic rhinitis, sneezing, blocked nose. All year January-December; itchiness in eyes; shortness of breath, difficulty breathing. Medication: gabapentin, saroten, esomeprazole, and diclofenac. Genetic. Intake of normal dose start before breakfast for 4 weeks. Perceived improvement on allergy, scale of 1 to 10 rated self as 5 out of 10; perceived improvement in general health, scale of 1 to 10 rated self as 5 out of 10 since Milmed treatment.

\section{Patient 5}

Male, 63-years-old, Non-smoker but snuff user. Childhood indications; eczema. History of allergy: pollen, dust, cat, scents. Seasonal, April-July. Symptoms: allergic rhinitis, sneezing, blocked nose, lower and ceased sense of smell; redness, itchiness, swollen and watery eyes; hoarseness, wheezing in the chest, loose and thick mucus. Medication; enalapril STADA. Not genetic. Intake of normal dose start before breakfast for 8 weeks, missed one week. Perceived improvement on allergy, scale of 1 to 10 rated self as 8; perceived improvement in general health, scale of 1 to 10 rated self as 8 , less infections, eczema, skin rash and itchiness since Milmed treatment.

\section{Patient 6}

Female, 52-years-old, Non-smoker exposed to passive smoking. Childhood indications: allergic rhinitis, food sensitivity. History of allergy: pollen, dust, cold air. Symptoms: allergic rhinitis, sneezing (April-August); itchiness, redness, and swollen eyes (MayAugust). Dust and cold air, JanuaryDecember. Medication: sumatriptan, migraine medication. Genetic. Intake of normal dose start before breakfast for 8 weeks. Perceived improvement on allergy, scale of 1 to 10 rated self as 7 , out of 10 ; perceived improvement in general health, scale of 1 to 10 rated self as 7 out of 10 , more alert, less colds and pain in body, better sleep since Milmed treatment.

\section{Patient 7}

Female, 46-years-old, Non-smoker. Childhood indications; allergic rhinitis, food sensitivity. History of allergy: pollen, grass, dog, cat, horse, fur, mites, dust, cold air, physical effort. Symptoms: blocked 
nose, sneezing, impaired sense of smell (January-December); itchiness, watery, and swollen eyes (April-September); wheezing in the chest, tough mucus, heavy breathing, difficult to breathe, pressure over the chest (January-December). Nongenetic. Intake of normal dose start before breakfast for 8 weeks. Perceived improvement on allergy, scale of 1 to 10 rated self as 10 , out of 10 ; perceived improvement in general health, scale of 1 to 10 rated self as 9 out of 10 , more alert, fewer colds and improved sleep since Milmed treatment.

\section{Patient 8}

Male, 30-years-old, Non-smoker but snuff user. Childhood indications: asthma/bronchial problems, allergic rhinitis. History of allergy: pollen, dust, cold air. Seasonal, April-September. Symptoms: allergic rhinitis, sneezing, blocked nose, lower and ceased sense of smell; redness, itchiness and watery eyes; irritation in throat; coughing, hoarseness, pressure on the chest, heavy breathing, loose and thick mucus. Medication, antihistamines. Non-genetic. Intake of normal dose start before breakfast for 10 weeks. Perceived improvement on allergy, scale of 1 to 10 rated self as 10; perceived improvement in general health, scale of 1 to 10 rated self as 10, more alert, fewer colds since Milmed treatment.

\section{Results}

The efficacy of Milmed treatment over at least 8 weeks was tested for by the patients' responses to several questionnaire health items, including:

Patients' subjective judgements concerned the following questions

A. Have you experienced any improvement due to the treatment associated with the alleviation of your allergy symptoms? Scale 1 to $10 \quad(1=$ no improvement; 10=symptom free).

B. Have you experienced any improvement due to the treatment in your general health status? Scale 1 to $10 \quad(1=$ no improvement; 10=large improvement).

The present results indicate clear evidence that the Milmed treatment markedly alleviated allergy symptoms among the patients who received compositions comprising treated Saccharomyces cerevisiae as described in the patent application.

Table 1. Responses of Milmed-treated $(\mathrm{N}=8)$ and Non-treated $(\mathrm{N}=8)$ patients presenting allergy symptoms and health characteristics.

\begin{tabular}{|c|c|c|}
\hline Group & $\begin{array}{c}\text { Self-assessed Allergy level } \\
\text { improvement on a scale from 1 to 10 }\end{array}$ & $\begin{array}{c}\text { Self-assessed General Health } \\
\text { Improvement on a scale from 1 to 10 }\end{array}$ \\
\hline $\begin{array}{c}\text { Treated } \\
\text { (“Milmed" group) }\end{array}$ & $8.38 \pm 0.62^{* *}$ & $7.38 \pm 0.82^{* *}$ \\
\hline Non-treated (Control group) & $1.50 \pm 0.26$ & $2.25 \pm 0.49$ \\
\hline${ }^{*} \mathrm{p}<0.02 ;{ }^{* *} \mathrm{p}<0.01$, pairwise t-tests, independent samples. \\
\hline
\end{tabular}


Thus, Table 1 indicates that there were both self-assessed allergy level significant improvements and self-assessed general health level improvements in comparison with the non-treated control group.

Due to extraneous circumstances, it was observed that not all the patients in the treated group were about to ingest the Milmed compound, as planned, on every week of the treatment period. Thus, correlational analyses were performed whereby the relationship of the number of weeks Milmed was taken by each patient and the self-assessed allergy level improvement, on one hand, and, selfassessed general health level improvements, on the other hand, were assessed.

Table 2: Pearson correlations analysis between Milmed number of treatment weeks and alleviation of allergy symptoms ${ }^{1}$ and improvement in general health ${ }^{2}$ by treated patients.

\begin{tabular}{|c|c|c|}
\hline & $\begin{array}{c}\text { Treatment Result }{ }^{1} \\
\text { (allergy improvement) }\end{array}$ & $\begin{array}{c}\text { Treatments Result }^{2} \\
\text { (health improvement) }\end{array}$ \\
\hline $\begin{array}{c}\text { Number of Treatment } \\
\text { weeks }\end{array}$ & $\mathrm{R}=0.624^{*}=0.656^{*}$ \\
\hline${ }^{*} \mathrm{p}<0.05$, one-tailed t-test.
\end{tabular}

With the exception of one patient, who had only consumed the Milmed during a fourweek period and therewith expressed only 50 percent alleviation, all the patients' evidenced marked improvements from their allergy symptoms, in most instances were symptom-free. In this context, the improvements in general health levels occasioned by the Milmed treatment were shown to be related to the number of weeks the treatment was taken (see Table 2, above). Once again, as observed with the former group of allergy patients [29], the therapeutic amelioration of patients' allergy symptoms, due to Milmed treatment, may be explained through the vagaries of the Milmed availability to these patients resulting from extraneous factors.

\section{Discussion}

The results of the present study may be summarized, as follows: (i) Milmed treatment over the 1o-week period improved markedly or abolished the extent of the allergies afflicting patients in the treatment group.

(ii) Milmed treatment over the 10-week period improved markedly the general health experience of the patients in the treatment group.

(iii) Among patients treated with Milmed, the level of allergy alleviation and general health status was related directly to the number of weeks they had taken the compound, as indicated by the correlational analysis (see Table 2).

The 'biotransference' of extremely high frequency-millimeter waves (EHF-MW), either directly or through the medium of treated yeast cells, was shown previously to engender therapeutic anti-inflammatory benefits. Biotransferance refers to the 
process through which a chemical or an element or even a living organism, such a yeast cells as probiotics, are absorbed from one organism by another, either through consumption or administration. The effect of MW interventions for immunologic conditions has been noted previously (see above), whereas other formulations for specific yeast-transference treatments have been found also to alleviate inflammatory conditions. Within this biologic context, it was observed in BALB/c laboratory mice that epicutaneous exposure to protein allergens together with staphylococcal enterotoxin B induced a T-helper (Th)-2dominant immune response (Th2 response) co-occurring with atopic dermatitis-like inflammation. However, oral administration of Saccharomyces cerevisiae legume-fermented product (SCLFP) attenuated the Th2 response observed through the reduced thickening of the epidermis, decreased eosinophil infiltration and lower levels of Il-5, Il-13 and CXCL11 expression in comparison with the control groups. The emergence of Milmed as a probiotic therapeutic entity in combination with burgeoning evidence for probiotic efficacy for anti-allergy/antiinflammatory actions may imply profound benefits for these conditions [30,31].

The status of Milmed as a probiotic, ingested as a suspension of yeast cells, the health advantages of which have been addressed previously [26]. Probiotics are live organisms present in foods, which yield health benefits related to their interactions with the gastrointestinal tract. In the MPTP-mouse model of Parkinsonism [24,25], it was observed the milmed-physical exercise combination restored repeatedly both functional motor activity and dopamine concentrations, as well as increasing markedly the levels of brain-derived neurotrophic factor (BDNF) in motor cortex regions. The antiinflammatory effects of probiotic therapies have been documented [32,33]. Under laboratory conditions, as opposed to providing sufferers with the probiotic compound to-be-ingested in the home environment, both immunologically stabilizing and anti-allergy alleviation was observed [34,35]. In this regard, the selection of particular probiotic strains, e.g. Saccharomyces cerevisiae and/or Saccharomyces carlsbergensis, induce actions upon the multiple, diversified and, as yet mainly undefined immune tolerance mechanisms [36]. Several different mechanisms have been studied, e.g. generation of cytokines from activated proT-helper type 1 after bacterial contact, regarding the anti-allergic effects of probiotics in stabilization of neuroimmunomodulatory activity and are currently under consideration [37]. Finally, several in vitro analyses have shown that Milmed induces anti-inflammatory in laboratory models utilizing lipopolysaccharides (LPS) as the proinflammatory component (unpublished data).

\section{Conclusions}

(a) The allergy level of patients of patients receiving Milmed (Saccharomyces cerevisiae treated as described in the patent application) was clearly improved by the Milmed treatment ( 8.38 versus 1.50 , see Table 1).

(b) The general health experience of patients receiving Milmed (Saccharomyces cerevisiae treated as described in the patent application) was markedly improved (7.38 versus 2.25 , see Table 1 ). 
(c) Both alleviation from allergy symptoms and general health status were related to the number of weeks the treated Milmed was ingested.

\section{Limitations}

In the previous study [29], an untreated Milmed paired control group was not

\section{References}

1. Loh W, Tang ML. The epidemiology of food allergy in the global context. Int J Environ Res Public Health. 2018;15(9):2043.

2. Ruokolainen L, Paalanen L, Karkman A, Laatikainen T, Von Hertzen L, Vlasoff T, et al. Significant disparities in allergy prevalence and microbiota between the young people in Finnish and Russian Karelia. Clin Exp Allergy. 2017;47(5):665-74.

3. Deifl S, Bohle B. Factors influencing the allergenicity and adjuvanticity of allergens. Immunotherapy. 2011;3(7):881-93.

4. Biedermann T, Winther L, Till SJ, Panzner P, Knulst A, Valovirta E. Birch pollen allergy in Europe. Allergy. 2019;74(7):1237-48.

5. Bousquet J, Bedbrook A, Czarlewski W, Onorato GL, Arnavielhe S, Laune D, et al. Guidance to 2018 good practice: ARIA digitally-enabled, integrated, person-centred care for rhinitis and asthma. Clin Transl Allergy. 2019;9(1):1-9.

6. FLORINCESCU-GHEORGHE NA, POPESCU F, DO ALEXANDRU FP. The Prevalence of Allergic Rhinitis to Ambrosia Elatior in Oltenia Area and the Association with Allergic Conjunctivitis or Asthma. Curr Health Sci J. 2019;45(1):66.

7. Bernstein DI, Schwartz G, Bernstein JA. Allergic rhinitis: mechanisms and treatment. Immunol Allergy Clin. 2016;36(2):261-78.

8. Numminen J. Allergic rhinitis. Duodecim; laaketieteellinen aikakauskirja. 2017;133(5):473-8.

9. Sicherer SH, Sampson HA. Food allergy: a review and update on epidemiology, pathogenesis, diagnosis, prevention, and management. J Allergy Clin Immunol. 2018;141(1):41-58.

10. Muche-Borowski C, Kopp M, Reese I, Sitter H, Werfel T, Schäfer T. German Society for Allergology and Clinical Immunology (DGAKI); Society of German Allergologists (ADA); German Society for Pediatric and Adolescent Medicine (DGKJ); German Society of Dermatology (DDG); German Society of Pediatric Allergology (GPA). Allergy prevention. J Dtsch Dermatol Ges. 2010;8(9):718-24.

11. Devyatkov N, Arzumanov Y, Betzkii O, Lebedeva N. Use of patently-controlled double-blind trials, MW therapy may low-intensity electromagnetic millimeter waves in medicine. Become an inexpensive and non-invasive adjunct 1oth Russian Symposium Millimeter Waves in Medicine therapy or even a monotherapy for some diseases. Biology. Moscow, Russia. 1995;6-8.

12. Efimov AS, Sit'ko SP. The theory of the sanatogenesis (the mechanism of the therapeutic effect) of microwave resonance therapy. Likars' ka sprava. 1993:111-5.

13. Dremuchev VA. Millimeter wave therapy in the outpatient Klinicheskaya Meditsina. 1994; 72:12-15.

14. Kutsenok V, Nikula T, Stechenko L. Ultrastructural features electromagnetic radiation of EHF-range on wound healing of duodenal mucosa in peptic ulcer patients treated with Fundamental and applied aspects of the use of millimeter electromagnetic radiation of the EHF-range. Likarska Sprava electromagnetic radiation in medicine, Kiev, Ukraine. 1995;5(6):93-7.

15. Efimov A, Ugarov B, Epshtein E, Zubkova S, Levenets L, 1979;2:65-8. Naumenko V, Efimov D, Danilova A. The effect of microwave resonance therapy on clinical and metabolic 56. Kabisov R. Millimeter waves in oncology: reality, problems, prospectives. Millimetrovye Volny v Biologii i Meditsine indices of diabetic patients. Terapevticheskij Arkhiv 1991;1992;1:55-61;63:51-4.

16. Shaposhnikov Y, Devyatkov N, Kamenev Y, Sarkisyan A, Toropov Y, Khomenko V. Clinical evaluation of use of low- Symposium 'Millimeter Waves in Medicine and Biology', Moscow, Russia, 1995:66-7. High intensity millimeter radiation in patients with infected wounds of limbs. In: Devyatkov N, ed. Millimeter Archer T | Volume 1; Issue 3 (2020) | Mapsci-JIA-1(3)-o17 | Research Article

Citation: Archer T, Erixon RM, Lenz T and Businaro R. Milmed Treatment Alleviates Symptoms of Allergy and Improves General Health. J Immuno Allerg. 2020;1(3):1-11. DOI: https://doi.org/10.37191/Mapsci-2582-6549-1(3)-017 
waves in 39. Zhukova T, Chaialo P, Chaika M. Microwave resonance medicine and biology. Moscow, IRE RAN, 1989:16-20.

17. Zhukova T, Chaialo P, Chaika M. Microwave resonance medicine and biology. Moscow, IRE RAN. Therapy in the treatment of patients with duodenal ulcer. 1994;54: 16-20.

18. Kolosova LI, Akoev GN, Ryabchikova OV, Avelev VD. Effect of low-intensity millimeter-range electromagnetic irradiation on the recovery of function in lesioned sciatic nerves in rats. Neurosci Behav Physiol. 1998;28(1):26-30.

19. Spacova I, Ceuppens JL, Seys SF, Petrova MI, Lebeer S. Probiotics against airway allergy: host factors to consider. Dis Model Mech. 2018;11(7):dmmo34314.

20. Korpan N, Resch K, Kokoschinegg P. Continuous 86. Gunko VT, Kozshina NM. Some complications of extremely microwave enhance the healing process of septic and high frequency therapy. Millimetrovye Volny v Biologii i aseptic wounds in rabbits. J Surgical Res. 1994;57:667-71.

21. Rojavin MA, Ziskin MC. Medical application of millimetre waves. QJM: monthly journal of the Association of Physicians. 1998;91(1):57-66.

22. Gedymin LE, Golant MB, Kuznetsov AP, Mudrik DG, Kolpikova TV, Balakireva LZ. The use of yeast living cells as a biological retranslation media for the therapeutic EHF effects. Millimeter Waves Biology and Medicine. 1999;16:10-5.

23. Archer T, Fredriksson A. The yeast product Milmed enhances the effect of physical exercise on motor performance and dopamine neurochemistry recovery in MPTP-lesioned mice. Neurotox Res. 2013;24(3):393-406.

24. Archer T, Fredriksson A. Pharmacogenomics and personalized medicine in Parkinsonism. Springer, New Delhi. InOmics for personalized medicine. 2013;265-287.

25. Archer T, Garcia D, Fredriksson A. Restoration of MPTP-induced deficits by exercise and Milmed ${ }^{\circledR}$ co- $^{-}$ treatment. PeerJ. 2014;2:e531.

26. Golant MB. Physical laws of medicine and their use in the realization of interaction of living organisms with EHF radiation. Radiophysics and quantum electronics. 1994;37(1):45-7.

27. Golant MB, Mudrik DG, Kruglyakova OP, Izvol'Skaya VE. Effect of EHF-radiation polarization on yeast cells. Radiophysics and quantum electronics. 1994;37(1):82-4.

28. Archer T, Rose Mary Erixon RM, Lenz T, Businaro R. Milmed treatment alleviated or abolished allergy. J Immunol Allergy. 2020;1:1-13.

29. Cuello-Garcia CA, Brożek JL, Fiocchi A, Pawankar R, Yepes-Nuñez JJ, Terracciano L, et al. Probiotics for the prevention of allergy: a systematic review and meta-analysis of randomized controlled trials. J Allergy Clin Immunol. 2015;136(4):952-61.

3o. Shu SA, Yuen AW, Woo E, Chu KH, Kwan HS, Yang GX, et al. Microbiota and Food Allergy. Clin Rev Allergy Immunol. 2019;57(1):83-97.

31. Doenyas C. Gut microbiota, inflammation, and probiotics on neural development in autism spectrum disorder. Neuroscience. 2018;374:271-86.

32. Suez J, Zmora N, Segal E, Elinav E. The pros, cons, and many unknowns of probiotics. Nat Med. 2019;25(5):716-29.

33. Forsythe $\mathrm{P}$. The nervous system as a critical regulator of immune responses underlying allergy. Curr Pharm Des. 2012;18(16):2290-304.

34. Wan ML, Forsythe SJ, El-Nezami H. Probiotics interaction with foodborne pathogens: a potential alternative to antibiotics and future challenges. Crit Rev Food Sci Nutr. 2019;59(20):3320-33.

35. Paparo L, Nocerino R, Di Scala C, Della Gatta G, Di Costanzo M, Buono A, et al. Targeting food allergy with probiotics. In Probiotics and Child Gastrointestinal Health. Springer, Cham. 2019; 57-68.

36. Hajavi J, Esmaeili SA, Varasteh AR, Vazini H, Atabati H, Mardani F, et al. The immunomodulatory role of probiotics in allergy therapy. J Cell Physiol. 2019;234(3):2386-98. 